of genes as envisaged in contemporary genic theory. No micro-theory can yet be offered; but the kind that would be satjsfying would be one in which, as in crystal structure, the organism could be envisaged as being constructed of small repetitive units.

It is difficult, in a short review, to give an adequate idea of the contents of this volume, or essay, for it is essentially an extended discussion. The reader, however, may be assured that it not only touches on many of the main features of morphogenesis, as presently understood, but also that it is the product of much thought and bears the impress of a philo sophic mind.

C. W. WARDLAW

\section{GENERAL DISCUSSIONS ON CHEMISTRY}

Heterogeneous Catalysis

(Discussions of the Faraday Society, No. 8.) Pp. 366. (Aberdeen: Aberdeen University Press, Ltd., 1950.) 30s. net.

Colloques Internationaux du Centre National de la Recherche Scientifique

10: Réactions dans l'état solide, Paris, Octobre 1948. Pp. iv +222. 1100 francs ; 25s. 30 : Rearrangements moléculaires et inversion de Walden, Montpellier, 24-29 avril 1950. Pp. 152. 2000 francs; 44s. (Paris: Centre National de la Recherche Scientifique ; London: H. K. Lewis and Co., Ltd., 1949-51.)

Institut International de Chimie Solvay

Huitième Conseil de Chimie tenu à l'Université de Bruxelles du 10 au 15 Septembre 1950. Le mécanisme de l'oxydation; Rapports et discussions. Pp. ïi+ 503. (Bruxelles: R. Stoops, 1950.) 550 francs.

A LTHOUGH general discussions and symposia on I selected topics are recognized features of scientific life, it is somewhat doubtful whether the publication of the proceedings contributes very much to the edification of the general reader. The papers presented are not often novel and generally consist of material already published, presented in such an abbreviated form that they are unintelligible except to specialists, and the discussion is usually chaotic and composed of fragments which are mutually selfdestructive. The Faraday Society seems to have felt this situation, since its discussions are prefaced by summaries or surveys which try to make some sort of coherent picture of what occurred. It is no doubt true that the proceedings are stimulating to the participants; but the average scientific reader, in search of concrete information, may sometimes feel that, having fulfilled this purpose, they might well have ended there. A report prepared by an independent author is usually much more intelligible and informative.

The Faraday Society discussion on heterogeneous catalysis comes off rather well in these respects, since it includes some important new material in the experimental field, and although the subsequent discussions of the papers are on the familiar lines, they do not occupy too much valuable space. The introductory paper, by Prof. H. S. Taylor, is readable and informative. Some of the outstanding difficulties and contradictions in the field are dealt with in other papers. The section on techniques brings together some valuable information on modern methods. The whole volume is well above the usual standard of such discussions and cannot fail to be useful both to specialists and those whose interests are more general.

The two "Colloques Internationaux" are less praiseworthy. The articles are too numerous and too brief to be wholly intelligible, and the volumes leave a feeling of surfeit and mental dyspepsia, which they are bound to produce in such a form. The topics are of great interest and importance; but the treatment as a whole does not present a coherent picture of the state of the subjects. All the same, the volumes will be found useful in a limited field. Readers who know little of the subjects will not know very much more after reading the fragments. It is suggested that a smaller number of contributions, more adequately treated and with some regard to the needs of non-specialists, would be more suitable. No doubt the participants gained much from the proceedings; but they might well have been satisfied with this and let the matter rest. May we hope that future publications will be more attractive to the general scientific reader?

The report of the eighth Solvay Congress contains some papers of reasonable length, carefully prepared and clearly presented. They are all intelligible and valuable, and a reader will gain real information from them. The field covered is wide, and includes the important biological aspects. The authors do not assume that the reader already knows what is in the papers, and in general lay the foundations well. The mathematical treatment is limited to what is really essential, and is adequately related to the experimental material. The discussions are often confused and unnecessary. The bibliographies are extensive and good. The subject of the mechanism of oxidation, in its present stage of development, is difficult and most important, and this volume may be said to clarify and unify a good deal of scattered material in a very satisfactory way. Some important newer reagents such as periodic acid have found extensive applications but are still not adequately treated in the detailed text-books. They are well represented here. The whole volume is sure of a welcome from many kinds of readers. J. R. PARTINGTON

\section{BRITISH AMATEUR ORNITHOLOGIST'S VADE-MECUM}

The Pocket Guide to British Birds

By R. S. R. Fitter. Pp. xvi $+240+112$ plates. (London and Glasgow : Wm. Collins, Sons and Co., Ltd., 1952.) 21s. net.

THIIs text-book aims at presenting British birds accurately to the beginner by coupling $\mathrm{Mr}$. R. A. Richardson's fine illustrations with the use, not of measurements and technical descriptions, but of a simple classification into eight groups : very short, short, medium short, medium, medium long, long, very long, and huge. There are also wing, neck, leg and bill ratios in similar categories. It seems a pity that the length of each bird is not given in inches, so that if the student finds himself very close to, or able to handle, a wild bird, he can check by measurement. To some extent the artist has overcome this difficulty by providing a silhouette of a sparrow upon each page of illustrations.

The beginner who may be at first confused by the novel classification in this book should take heart from Mr. Fitter's observation that even the expert cannot be confident about the identity of some of 